\title{
Process Optimization of Preparation for Si-Al alloy by Carbon Reduction Coal Fly Ash
}

\author{
Zhiling Bai ${ }^{1, a}$, Bingke Qin ${ }^{1,2, b}$, Minglei Lian ${ }^{1, c}$, Yingju Miao ${ }^{1,3, d}$
}

${ }^{1}$ School of Chemistry and Materials Engineering, Liupanshui Normal University, Liupanshui,China

${ }^{2}$ College of Materials and Metallurgy, Guizhou University, Guiyang, China

${ }^{3}$ School of Chemical Engineering,Kunming University of Science and Technology, Kunming,China

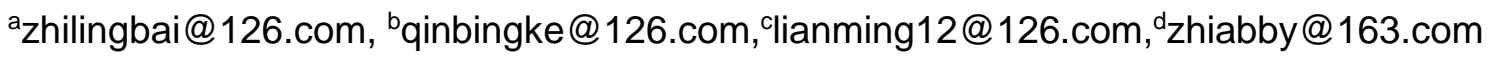

Keywords: coal fly ash; Si-Al alloy; HSC chemistry; reduction;carbon

Abstract. The influence of different carbon content and temperature on the carbothermal reduction coal fly ash and the optimum conditions of carbothermal reduction coal fly ash were investigated. The effect of temperature on the equilibrium components of coal fly ash during carbon reduction process was simulated by using HSC Chemistry 6.0 software. The content of aluminum and silicon were calculated. The results showed that the content of $\mathrm{Si}$ and $\mathrm{Al}$ were increased with the increase of temperature.During the reduction of coal fly ash with carbon, the silica was preferentially reduced. When the carbon content was $36 \%$, the content of silicon was the largest, and the amount of silicon was increased gradually with the increase of temperature. The optimum carbon content of aluminum oxide in coal fly ash was $28 \%$, and the recovery of aluminum was decreased with the increase of carbon content.

\section{Introduction}

Coal fly ash is the main solid waste from coal-fired power plants.Coal fly ash is one of the industrial waste residue with large displacement in our country. With the development of power industry, the amount of coal fly ash emissions from coal-fired power plants has increased year by year. A large amount of coal fly ash is not treated, coal fly ash will produce the dust and air pollution. Coal fly ash is discharged into the water system will cause the river blockage, and one of the toxic chemicals will cause harm to human and biological.Therefore, the processing and utilization of coal fly ash has attracted extensive attention. Si-Al alloy is widely used in steel, transportation and other fields[1].The current production methods are used infiltration method and carbon thermal method, the relative cost of carbon thermal method is low. The chemical composition of coal fly ash are mainly $\mathrm{SiO}_{2}$ and $\mathrm{Al}_{2} \mathrm{O}_{3}$, and preparation of Si-Al alloy using coal fly ash has low price, wide source of raw materials.It can reduce the production cost of Si-Al alloy, and removal of a large amount of coal fly ash near the thermal power plant will enable the industrial solid waste to be recycled[2].

\section{Research methods}

HSC Chemistry is one of the world's famous chemical thermodynamic software, which has been adopted by many scientific researchers[3-5]. The main function of HSC Chemistry software is to calculate the thermodynamic parameters of various chemical reactions and simulate the balance of chemical reactions. The Equilibrium Composition module is mainly used to simulate the equilibrium state of chemical reactions. The main theoretical basis of the simulation process is the principle of minimum Gibbs free energy.By using the Equilibrium composition module of HSC Chemistry 6.0 chemical thermodynamics software, the thermodynamic equilibrium component can be determined by the simulation calculation of the chemical reaction process of carbon reduction coal fly ash. 


\section{Results and discussion}

\section{Effect of temperature to equilibrium composition.}

The relationship between the equilibrium composition of the reaction system and the ambient temperature at different reaction temperature at the molar ratio $\left(\mathrm{C}: \mathrm{Al}_{2} \mathrm{O}_{3}: \mathrm{SiO}_{2}=10.9: 1: 3.3\right)$ are shown in Fig.1. As can be seen from Fig.1, the process of carbon reduction of coal fly ash is very complex, and the equilibrium composition of the system at different temperature can be visually observed. Fig. 1 illustrates that carbon begin to participate in the reaction at $1400{ }^{\circ} \mathrm{C}$, and the content of silica begin to decrease while $\mathrm{CO}$ generation.At this time, carbon reacts with silica.At $1800{ }^{\circ} \mathrm{C}$, the content of $\mathrm{SiO}_{2}$ is almost zero. The content of $\mathrm{Al}_{2} \mathrm{O}_{3}$ begin to decrease at $1800{ }^{\circ} \mathrm{C}$, and $\mathrm{Al}_{4} \mathrm{CO}_{4}$ and $\mathrm{Al}_{2} \mathrm{CO}$ are created.With the increase of temperature, the content of $\mathrm{Al}_{2} \mathrm{O}_{3}$ is decreased and the content of $\mathrm{Al}_{4} \mathrm{CO}_{4}$ and $\mathrm{Al}_{2} \mathrm{CO}$ are increased first then decreased.At $2200{ }^{\circ} \mathrm{C}$, the content of $\mathrm{Al}_{4} \mathrm{CO}_{4}$ and $\mathrm{Al}_{2} \mathrm{CO}$ are reduced to zero.At $1500{ }^{\circ} \mathrm{C}$, silicon carbide is formation. With the increase of temperature,the content of $\mathrm{SiC}$ is increased gradually. The reaction of generating silicon carbide is the strongest in the temperature range of $1500{ }^{\circ} \mathrm{C}-1600{ }^{\circ} \mathrm{C}$, but with the further increasing of temperature, the degree of reaction is getting lower and lower. When the temperature exceeds $2000{ }^{\circ} \mathrm{C}$, the content of $\mathrm{SiC}$ in the equilibrium composition is gradually decreased,so $\mathrm{SiC}$ as a reactant begin to participate in the reaction. When the system temperature exceeds $2000{ }^{\circ} \mathrm{C}$, silicon and aluminum are appeared. The results indicate that there has been reduction reaction of silicon and aluminum, with the increase of temperature, the equilibrium mole number gradually are increased. When the temperature reaches $2100{ }^{\circ} \mathrm{C}$, the equilibrium mole number of Si does not change, it tends to be constant. When the temperature reaches $2200{ }^{\circ} \mathrm{C}$, the equilibrium mole number of $\mathrm{Al}$ is basically unchanged. At this temperature, the reduction reaction can theoretically proceed to the end. This trend can also be derived stabilized according to the content of CO remained stable at $2200{ }^{\circ} \mathrm{C}$.Carbides of silicon and aluminum can be easily formed at low temperature stage[6].Therefore, increasing the system temperature rapidly and avoiding the reaction at the low temperature stage can improve the yield of silicon and aluminum.

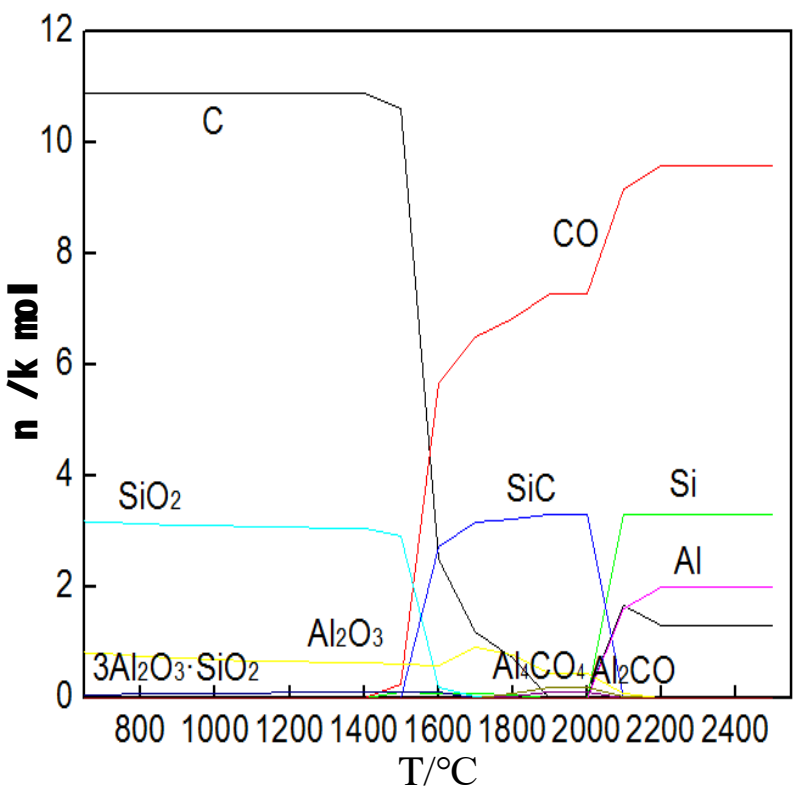

Fig.1 Effect of temperature to equilibrium composition

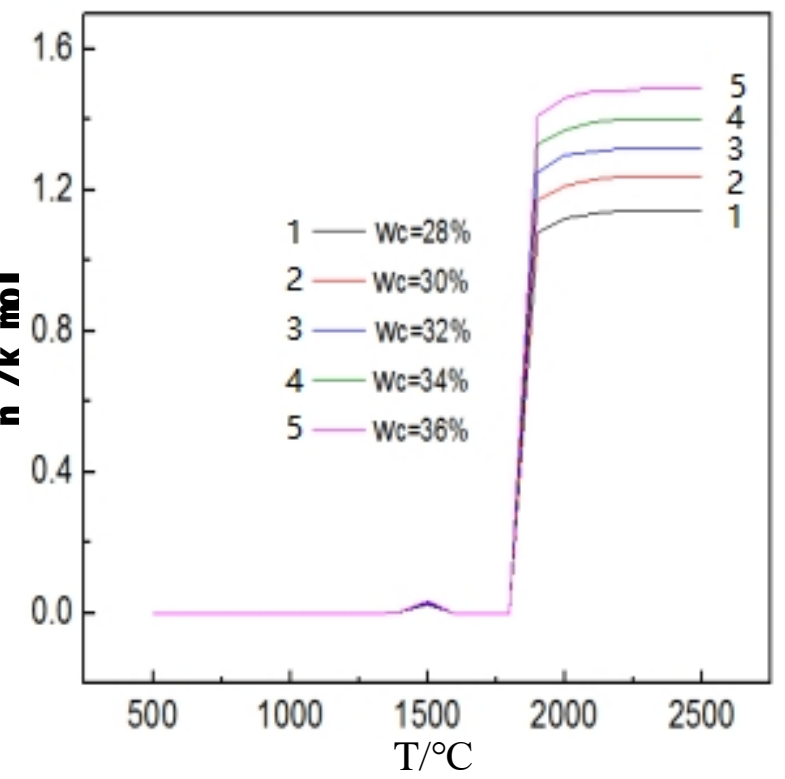

Fig.2 Effect of temperature and carbon amount on the content of silicon in system equilibrium

\section{Effect of temperature and carbon amount on the content of silicon in system equilibrium.}

Fig. 2 shows effect of temperature and carbon amount on the content of silicon in system equilibrium. The effects of temperature on the equilibrium content of $\mathrm{Si}$ are $28 \%, 30 \%, 32 \%, 34 \%$ and 36\%, respectively. As shown in Fig.2, in the condition of the content of carbon are 28\%, 30\%, $32 \%, 34 \%, 36 \%$ respectively, the content of $\mathrm{Si}$ is increased gradually with the increase of 
temperature. At $2200{ }^{\circ} \mathrm{C}$, the reduction of $\mathrm{Si}$ is the largest, and the equilibrium content of $\mathrm{Si}$ is increased gradually with the increase content of carbon. The results indicates that excess carbon can cause the silicon carbide to react in the direction of silicon generation.Therefore, the optimum content of carbon and temperature (with minimum carbon content of $28 \%$ and temperature of $2000^{\circ} \mathrm{C}$ ) should be the best for $\mathrm{Si}$.

\section{Effect of temperature and carbon amount on the content of aluminum in system equilibrium.}
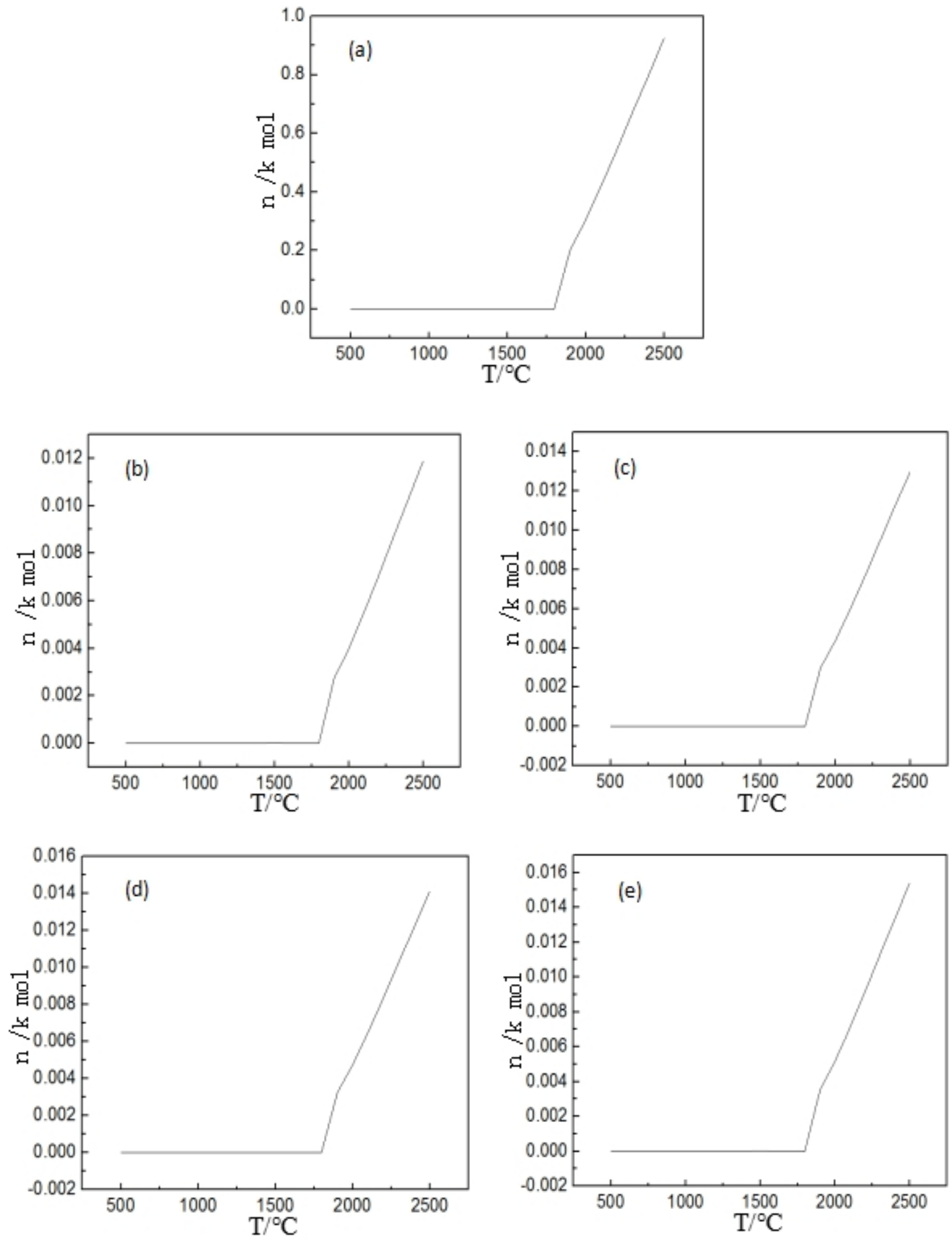

Fig. 3 Effect of temperature and carbon amount on the content of aluminum in system equilibrium (a) Wc=28\%; (b) Wc=30\%; (c) Wc=32\%; (d) Wc=34\%;(e) Wc=36\% 
Fig. 3 shows the effect of temperature and carbon amount on the content of aluminum in system equilibrium. The effects of temperature on the equilibrium content of $\mathrm{Al}$ are $28 \%, 30 \%, 32 \%, 34 \%$ and $36 \%$, respectively.From Fig.3 (a) $\sim(b)$, it can be seen that under the conditions of different carbon ratio, $\mathrm{Al}$ has been generated at $1800{ }^{\circ} \mathrm{C}$, and with the increase of temperature, the content of $\mathrm{Al}$ is increased gradually. Under the same temperature, the amount of carbon allocated has a certain influence on the reduction of aluminum. With the increase of carbon content, the content of $\mathrm{Al}$ is decreased first and then increased. When the temperature is constant and the carbon content is $28 \%$, the maximum amount of $\mathrm{Al}$ is generated. When a certain temperature, the carbon content are $30 \%$, $32 \%, 34 \%, 36 \%$,respectively, the content of $\mathrm{Al}$ in the balance system has little difference. With the increase of carbon content, the amount of $\mathrm{Al}$ is decreased, which might be the formation of $\mathrm{Al}_{3} \mathrm{C}_{4}$. The increase of temperature is beneficial to the reduction of alumina, but the volatilization loss of gaseous substance is increased[6]. Therefore, the temperature of preparation of Si-Al alloy by carbon reduction coal fly ash should not be too high.

\section{Conclusions}

The suitable reaction temperature range of preparation of $\mathrm{Si}-\mathrm{Al}$ alloy by carbon reduction coal fly ash is from $2000{ }^{\circ} \mathrm{C}$ to $2200{ }^{\circ} \mathrm{C}$. There are many side reactions in the temperature range, and the reaction temperature has a great influence on the equilibrium composition. During the reduction of coal fly ash with carbon, the silica is preferentially reduced. When the carbon content was $36 \%$, the content of silicon was the largest, and the amount of silicon was increased gradually with the increase of temperature. The optimum carbon content of aluminum oxide in coal fly ash was $28 \%$, and the recovery of aluminum was decreased with the increase of carbon content.

Therefore, increasing the system temperature rapidly and avoiding the reaction at the low temperature stage can improve the yield of silicon and aluminum.

\section{Acknowledgments}

This work was financially supported by the Guizhou Provincial Science and Technology Foundation (No.[2014]7460),Solid Waste Recycling Laboratory of Coal Utilization(No.2011-278), the Liupanshui Normal University High-Level Talent Research Start Foundation (LPSSYKYJJ201 417), and Guizhou province ordinary college innovation team of mineral processing and comprehensive utilization of scientific and technological (No.[2015] 69).

\section{References}

[1]Xie Keqiang,Liu Ziliang,Ma Wenhui,et al.J.Kunming Uni.Sci.Techno.( Natural Science Edition). Vol.40(2015),p.1-7. In Chinese

[2]Y.L.Saraswathi,S.Das,D.P.Mondal.Mater.Sci.Eng A.Vol.3(2006),p.11-21.

[3]Kikuo Nakanoa,Norihiko Fukatsua, Yoshinori Kanno.CalPhad,2009,33(2):343-352.

[4]C.A.Pickles..Joumal of Hazardous Materials,2009,166(2-3):1030-1042.

[5]P.Lohsoontorn,D.J.L.Brett,N.P.Brandon.Joumal of Power Sources, 2008,175(1):60-67.

[6]Li Ziyong,Wu Chunhan,Yu qingchun,et al.J.Chin. Coal Soc.Vol.41(2016),p.769-775. In Chinese 